\begin{tabular}{c|c|c}
\hline \hline & CLIMATE RESEARCH & Published May 23 \\
Vol. 21: 27-42, 2002 & Clim Res & \\
\hline
\end{tabular}

\title{
Local versus remote grid points in climate downscaling
}

\author{
Waltraud A. R. Brinkmann* \\ Department of Geography, University of Wisconsin-Madison, 213 Science Hall, 550 North Park Street, Madison, \\ Wisconsin 53706, USA
}

\begin{abstract}
The association between daily as well as monthly winter precipitation and concurrent $700 \mathrm{hPa}$ heights for 3 different North American precipitation regimes was examined using correlation fields and a typing of daily $700 \mathrm{hPa}$ height patterns. Wet days, regardless of circulation type, were found to be associated with negative height anomalies immediately to the west or northwest of the precipitation regions, at the 'local' grid point. These small-scale height anomalies were found to represent traveling short waves that were missed by the circulation typing scheme. The correlation fields between monthly precipitation and concurrent $700 \mathrm{hPa}$ heights revealed a westward shift of the height minima to a location west of $100^{\circ} \mathrm{W}$, to a 'remote' grid point. The nature of these remote minima was examined using the 10 wettest and 10 driest months. Decomposition of the height anomalies at the remote grid points into between-type and within-type contributions revealed that while some of the negative heights during wet months are due to an increase in the frequency of circulation patterns with below normal heights (such as troughs or weak ridges), more than two-thirds of the contribution comes from height depressions superimposed upon the larger-scale patterns and most of these are associated with positive vorticity. This leads to the conclusion that the correlation minima west of $100^{\circ} \mathrm{W}$ at the monthly time scale reflect the frequent generation of short waves during wet months over the well-known North American cyclogenetic region east of the Rocky Mountains. These results have 2 implications with respect to statistical downscaling. First, regarding techniques designed to extract information from a single grid point: the optimum grid point location may be a function of the time scale under consideration. Second, regarding techniques designed to extract information from large-scale circulation patterns: the difficulties in capturing the very important but small short waves limit their usefulness.
\end{abstract}

KEY WORDS: Precipitation $\cdot 700 \mathrm{hPa} \cdot$ Circulation pattern typing $\cdot$ North America $\cdot$ Downscaling Resale or republication not permitted without written consent of the publisher

\section{INTRODUCTION}

General circulation models (GCMs) capture the most important mean features of the global climate but their representation of climates at the regional scale tends to be poor (IPCC 1996). This has led to a growing body of work concerned with downscaling - the translation of coarse-grid GCM output into regional climate conditions using dynamic and empirical approaches (Georgi \& Mearns 1991, Wilby \& Wigley 1997). Dynamic approaches involve embedding a high-resolution re-

*E-mail: brinkmann@geography.wisc.edu gional model within a GCM; the long-term integrations needed for climate studies are still, however, computationally demanding. Empirical approaches involve building statistical relationships between atmospheric variables and the local climate.

Most empirical approaches utilize information derived from either the nearest grid point (or radiosonde station) or from the circulation pattern within a map window that encloses several grid points, in order to define the local climate. The circulation pattern approach is appealing because it is founded upon synoptic and physical principles, and because GCMs are most credible within this resolution. The choice of the size and location of the map window is, however, criti- 
cal to this approach since the circulation features of significance to the local climate need to be captured. Most investigators place the window over and to the west of the area of interest because weather systems travel from west to east. Using information from the nearest grid point also makes physical sense because the atmospheric conditions at the nearest point should be most similar to those over the area of interest. However, it has been shown that for some parts of the country the strongest correlation between local precipitation and geopotential heights is not at the nearest (local) but at a remote grid point (generally to the west of the area of interest).

Specifically, Stidd (1954) computed correlation fields between $700 \mathrm{hPa}$ heights and a series of state-wide precipitation totals for winter months and found that almost all of them displayed a center of large negative correlations over western North America. Klein (1963; hereafter K63), working with 5 d rather than monthly precipitation totals and dividing the country into 40 regions, found that the center of negative correlation was for almost all regions located west of $100^{\circ} \mathrm{W}$ (Fig. 1), in agreement with Stidd (1954). Assuming that areas of negative correlations represent long wave troughs, K63 developed a schematic model for precipitation in relation to an upper-level long-wave pattern. Because most correlation minima in Fig. 1 are located west of $100^{\circ} \mathrm{W}$, the model implies that the optimum location of a trough for most parts of the country is west of $100^{\circ} \mathrm{W}$, over western North America. This is some-

what surprising because a long-wave trough occurs infrequently in that location in winter (e.g. Burnett 1994).

Brinkmann (2000; hereafter B00), exploring the association between daily precipitation totals for the Lake Superior basin and concurrent $700 \mathrm{hPa}$ heights, also found negative height deviations at some distance to the west of the lake on wet days. However, the center of the height depressions was located only half the distance indicated in K63; it was furthermore interpreted in B00 as a small-scale feature, a traveling short wave, rather than a long-wave trough.

Comparison of the results obtained in K63 and B00 raises the question: Is the difference in the location of the maximum negative correlation and the negative height deviations physically significant or is it due to differences in the data and/or methods used? It will be shown here that the difference is time-scale related. At the daily time scale, the height depression reflects a short wave in the vicinity of the precipitation station or region; at the longer (5 d or monthly) time scale, it reflects the frequent generation of short waves over western North America. This difference, which has implications for downscaling, has never been documented.

Investigations of the relationship between regional precipitation and atmospheric pressure variables are numerous, although many focus on sea level pressure rather than geopotential heights. Yet, upper-level or 'free-atmosphere' variables are not as much affected by local surface conditions, and a

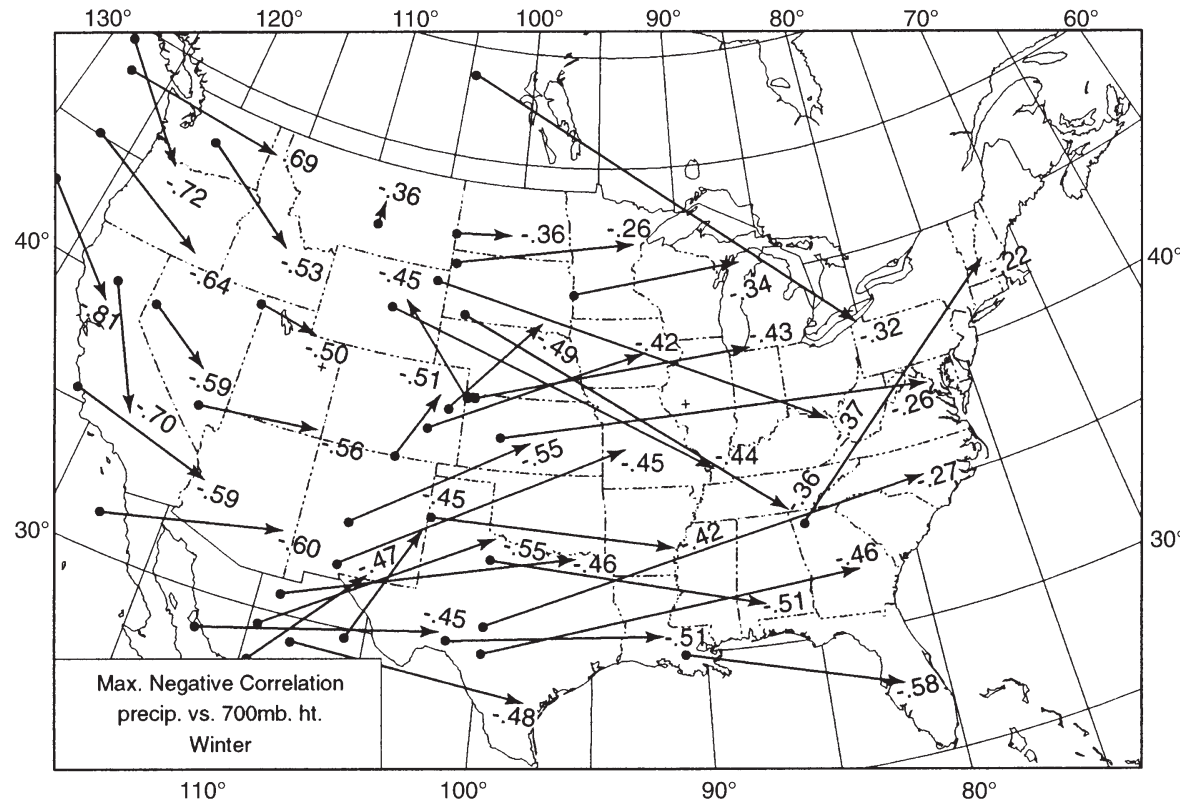

Fig. 1. Maximum negative correlations between $5 \mathrm{~d}$ precipitation totals and concurrent mean $700 \mathrm{hPa}$ height anomalies (solid dot $=700 \mathrm{hPa}$ grid point, tip of arrow $=$ center of precipitation region, number next to it = correlation coefficient) (Klein 1963) growing number of studies is showing that model-generated upper-air variables are in many cases more realistic than surfacebased variables (Portman et al. 1992, Hewitson \& Crane 1996, Palitukof et al. 1997, Sailor \& Li 1999). Of those studies linking precipitation to geopotential heights, only a few have tried to identify the 'best' grid point, and none have explored a possible difference in the location of such grid points at different time scales.

Many studies have used the geopotential height at the nearest grid point as a predictor of local precipitation, often in conjunction with a range of other variables, frequently at different levels (e.g. Walsh et al. 1982, Cayan \& Roads 1984, Karl et al. 1990, Wigley et al. 1990, Easterling 1999). The assumption is that conditions at 
the local grid point or nearest radiosonde station are representative of the larger region and no search for a better grid point is undertaken. In a few studies, a search is made for the best set of geopotential height predictors (usually 3 to 5 ) to be included in a regression model (e.g. Klein \& Bloom 1987, 1989). However, there is no interest in identifying 'the best', since the focus is on the combination of points that maximize the variance accounted for. An exception to this is the study by Klein \& Bloom (1989), which lists the best predictors for 2 locations. The grid point whose monthly mean 700 $\mathrm{hPa}$ heights accounted for most of the precipitation variance was found to be located $500 \mathrm{~km}$ to the northwest of a station located in northern California but $1100 \mathrm{~km}$ to the west of a station in North Carolina; the regression coefficient was negative in both cases. Artificial neural networks (ANNs), a type of nonlinear multiple regression, are increasingly being used in climate studies, including the downscaling of local precipitation from geopotential heights (e.g. Hewitson \& Crane 1996, Crane \& Hewitson 1998, Cavazos 1999). However, the goal is again to maximize the variance accounted for rather than to identify the best grid point.

Studies using circulation indices by definition focus on the presence or absence of a very specific pattern of geopotential height anomalies. The Pacific North American (PNA) pattern, for example, which is the most important teleconnection pattern for North America, consists of 3 'centers of action', each contributing to the PNA index. Because there are large variations in the strength of the individual centers, a correlation between the index and local precipitation (for example, Yarnal \& Leathers 1988, Leathers et al. 1991, Redmond \& Koch 1991) contains little information on that portion of the pattern most important to the precipitation region.

Numerous studies have linked local precipitation to circulation patterns. Daily geopotential height maps are either grouped into similar types using a correlation-based approach or they are decomposed into principal components (PCs), and the frequency of occurrence of the types or the magnitude of the PC scores is then related to precipitation using a multiple regression or ANN approach or a stochastic weather generator (e.g. Harnack \& Lanzante 1985, Bardossy \& Plate 1992, Matyasovszky \& Bogardi 1994, Hewitson \& Crane 1996). Again, the focus is on maximizing the variance accounted for rather than on the identification of the portion of the circulation pattern of greatest importance to the precipitation region.

In some studies, composite maps of geopotential height anomalies for wet months or cross-correlation maps between monthly mean geopotential heights and concurrent local precipitation are displayed and the pattern is interpreted in terms of the anomalous component flow from the moisture source region (e.g. Walsh et al. 1982, Klein \& Bloom 1987, Bonsal et al. 1999, Robertson \& Ghil 1999). The location of the area of largest (negative) height anomalies or largest negative correlation coefficients on such maps agrees with those presented by Stidd (1954) and in K63. It tends to be located in the vicinity of precipitation stations located in western North America but is displaced to the west of the station (generally west of $100^{\circ} \mathrm{W}$ ) for precipitation stations located in the east.

Tests have been conducted on the effects of different spatial scales of gridded pressure data (e.g. Yarnal 1984) but not on the effects of different temporal scales. In at least 1 study, both daily and monthly data are used (Zorita \& von Storch 1999), but the purpose in that case was to test the performance of different downscaling methods (which required different input data).

The present study aims to investigate the difference in location of the key grid points at 2 different time scales. Specifically, the analysis of the association between daily summer precipitation for the Lake Superior basin and concurrent $700 \mathrm{hPa}$ heights reported in B00 is repeated here for the winter season and using daily as well as monthly data. Furthermore, 2 more precipitation regions, with distances to their respective centers of action greater than that for Lake Superior (Fig. 1), were selected for this study: Ohio, for which the correlation minimum in K63 is located at a distance of about $1600 \mathrm{~km}$ and not very far from that for the Lake Superior basin, and Georgia, for which the location of the correlation minimum is also at a distance of about $1600 \mathrm{~km}$ but located further south, over Texas. These 3 regions represent 3 different North American precipitation regimes: the Interior, the Ohio Transition, and the Subtropical Oceanic regimes (Trewartha 1981), or the Great Lakes, Ohio Valley, and Southeastern regions (Walsh et al. 1982). They were chosen to test the similarity of the results for different precipitation regimes.

In the next section a discussion of the dataset and methods used in this study is presented. This is followed in Section 3.1 by an analysis of the association between the precipitation for the 3 regions and the $700 \mathrm{hPa}$ heights at the daily time scale, and in Section 3.2 at the monthly time scale. The paper concludes with a summary of the findings and a discussion of implications for downscaling.

\section{DATA AND METHODS}

The analysis was restricted to the winter months of a 25 yr period (December 1962 to February 1987) for 

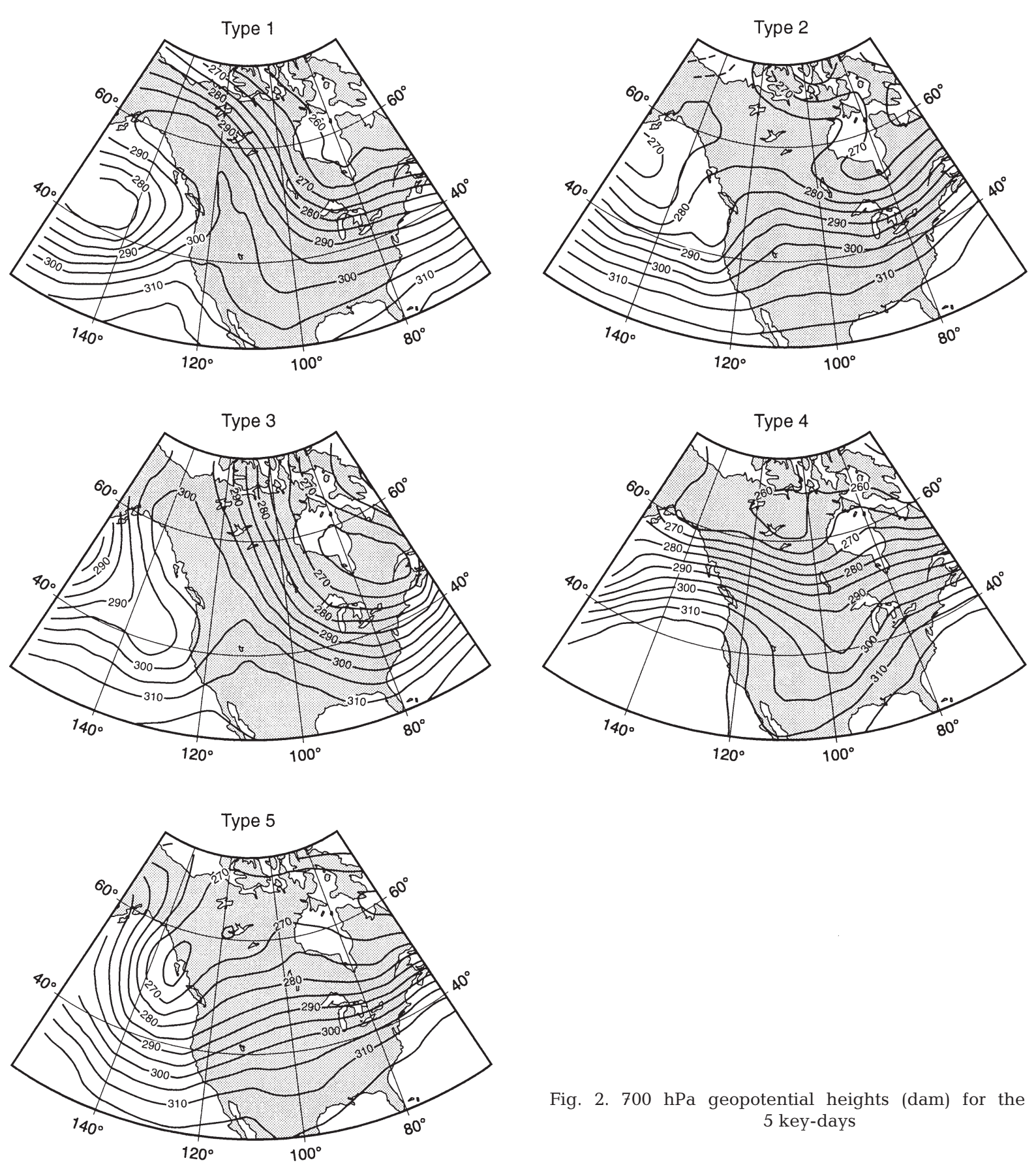

Fig. 2. $700 \mathrm{hPa}$ geopotential heights (dam) for the first 5 key-days

which daily $700 \mathrm{hPa}$ maps had been classified in an earlier study (Brinkmann 1999a; hereafter B99a). The data set thus consists of $2250 \mathrm{~d}$ or $75 \mathrm{mo}$.

\subsection{Precipitation data}

For the Lake Superior basin, daily precipitation totals for 6 stations located around the lake had been obtained from the Midwestern Climate Center (Cham-

paign, IL) and the Canadian Climate Center (Downsview, ONT) for the work presented in B99a. The station data were area-weighted and averaged to create daily values for the lake basin.

For the Ohio region, daily precipitation totals for 10 stations were used. Most of these stations are located within Ohio but a few West Virginia stations were also included. For the Georgia region, the data were the daily precipitation totals for 10 stations located mostly within Georgia and a few from northern Florida. For 
both regions, the data source is the NCDC 'Summary of the Day' files, and the stations were selected on the basis of length and completeness of record. Missing data were interpolated using the average of the 3 closest stations. The station data were not area-weighted (as compared to the Lake Superior region); the area covered by these stations is smaller, but almost twice as many stations were used. The station data were averaged to create a time series for each of the 2 regions. Although they are referred to here as 'regional' time series, they are not intended to be a true representation of the precipitation for the Ohio and Georgia regions but are a reflection of the desire to base the results of this exploration of the precipitation/geopotential height association at different time scales on more than 1 station within each of these regions.

Seasonal variations were removed from the regional time series by expressing the daily values as fractions of the $25 \mathrm{yr}$ mean for the Julian date and region. To simplify the analysis of the link between surface and upper-air conditions, the daily precipitation values were grouped into 3 classes - dry, average, and wetby ranking them and dividing the series into thirds. In this way, each class is equally likely. For each of the 3 regions, the dry class contains all days with zero fractions plus some days with very small fractions.

\subsection{Upper-air data}

As described in $\mathrm{B} 99 \mathrm{a}$, the $700 \mathrm{hPa}$ pressure data are the National Meteorological Center (NMC) twice-daily heights obtained from the National Center for Atmospheric Research (NCAR) data library. The twice-daily values were averaged to create daily maps. If 1 of the 2 maps for a day was missing, no averaging was performed. The entire day was declared missing if both observation times were missing (a total of $19 \mathrm{~d}$ ).

\subsection{Method}

\subsubsection{Circulation pattern classification}

The classification of daily $700 \mathrm{hPa}$ heights used in the present study is the one developed in B99a. The map window consists of a $6 \times 6$ (36 point) $4.5^{\circ}$ latitude by $7.5^{\circ}$ longitude grid (identical to the NCAR GCM grid); it extends from the Rocky Mountains into the Atlantic Ocean. In B99a, 4 windows were tested; the one used here was found to generate the best circulation classification for the Lake Superior basin and was also found to be superior to a classification based on principal components (Brinkmann 1999b).
The correlation-based pattern classification used in B99a was first introduced by Lund (1963) and modified slightly by others (Yarnal 1993). It consisted of correlating each daily map with every other daily map. The map-day with the largest number of correlations exceeding 0.5 was designated the key-day for Circulation Type 1. All Type 1 days were then removed from the analysis. The map-day with the next largest number of related maps was designated the key-day for Circulation Type 2, and so on. Since it is possible for 2 maps to be similar overall but to differ in 1 portion of the map, correlation coefficients between 6 corresponding map sectors were computed (3 double-rows or latitudinal sectors of 12 grid points each, and 3 double-columns or longitudinal sectors of 12 grid points each) to ensure similarity in all areas of the maps. They passed this similarity test if all 6 correlation coefficients exceeded 0.5. All correlations were then checked to ensure that each map was assigned to the circulation type with which it was most highly correlated. In the final step, maps belonging to types with fewer than 20 members were reclassified.

As described in B99a, this correlation-based classification generated 22 circulation types. The first 5 types account for $49.7 \%$ of the days; their key-day maps (for the entire North American sector, not just the 36-point window used for the classification) are shown in Fig. 2.

\subsubsection{Vorticity}

Geostrophic relative vorticity $(\zeta)$ at the $700 \mathrm{hPa}$ level was one of the tools used to interpret the negative height anomalies. This was computed using the centered finite-difference expression (Carlson 1991):

$$
\zeta=\frac{4 g}{d^{2} f}\left(\tilde{Z}_{i j}-Z_{i j}\right)
$$

where $g$ is the gravitational acceleration, $d$ is the distance between adjacent grid points, $f$ is the Coriolis parameter, $Z_{i j}$ is the geopotential height at grid point $(i, j)$, and $\tilde{Z}_{i j}$ is the geopotential field defined at grid point $(i, j)$ by:

$$
\tilde{Z}_{i j}=\frac{1}{4}\left(Z_{i+1, j}+Z_{i-1, j}+Z_{i, j+1}+Z_{i, j-1}\right)
$$

The window used to classify the daily circulation patterns in B99a was expanded here to a $8 \times 7$ (56 point) grid to compute the vorticity fields.

\section{RESULTS}

Given the differences in the approaches used in K63 and B00 in establishing the location of the $700 \mathrm{hPa}$ 
height minima, such as the time of year and the method of analysis, the present study begins with the computation of the correlation fields between daily precipitation and concurrent $700 \mathrm{hPa}$ grid point heights as well as between their monthly values (Fig. 3).

The daily correlation fields are characterized by a center of negative values immediately to the west of the 3 precipitation regions. This is very similar to the location of negative height differences between wet and dry days of a circulation type for summer precipitation over the Lake Superior basin found in B00. These minima will hereafter be referred to as 'local' minima and their location as 'local' grid points (although they are strictly speaking not local; i.e. not centered on the precipitation regions).

The monthly correlation fields are different from the daily (or $1 \mathrm{~d}$ ) correlation fields but are in good agreement with the $5 \mathrm{~d}$ fields in K63. The centers of the minima are shifted westward: they are located west of $100^{\circ} \mathrm{W}$ and over the northern Great Plains for Lake Superior and Ohio, but further south for Georgia. These latter will hereafter be referred to as 'remote' minima and their locations as 'remote' grid point. The westward progression of the minima with increasing averaging period is probably gradual and reflects the eastward travel of upper-level short waves (as will be shown later).

\subsection{Daily time scale: local minima}

The classification of daily $700 \mathrm{hPa}$ maps for 25 winter seasons generated in B99a for the purpose of studying the link between upper-level circulation patterns and surface air temperature is here used to explore the cause of the local minima. The circulation type frequencies for the first 5 types and their precipitation characteristics for the 3 regions are listed in Table 1.

Circulation Type 1, the most frequently occurring pattern (16\% of the days), consists of a steep ridge over

Table 1. Circulation type frequencies and precipitation characteristics

\begin{tabular}{|c|c|c|c|c|}
\hline \multirow{2}{*}{\multicolumn{2}{|c|}{$\begin{array}{l}\text { Circulation } \\
\text { Type } \quad \text { Frequency (\%) }\end{array}$}} & \multicolumn{3}{|c|}{$\begin{array}{c}\text { Frequency }(\%) \text { of precipitation } \\
\text { categories (dry/average/wet) }\end{array}$} \\
\hline & & Lake Superior & Ohio & Georgia \\
\hline 1 & 16.0 & $40 / 38 / 22$ & $52 / 30 / 18$ & $45 / 33 / 22$ \\
\hline 2 & 11.6 & $28 / 36 / 36$ & $19 / 33 / 48$ & $12 / 27 / 61$ \\
\hline 3 & 8.7 & $39 / 28 / 33$ & $25 / 50 / 25$ & $51 / 31 / 16$ \\
\hline 4 & 6.8 & $26 / 30 / 44$ & $28 / 21 / 51$ & $18 / 37 / 45$ \\
\hline 5 & 6.6 & $60 / 21 / 19$ & $49 / 43 / 8$ & $55 / 35 / 10$ \\
\hline First 5 types & 49.7 & & & \\
\hline Unclassified & 6.2 & & & \\
\hline
\end{tabular}

the Rocky Mountains and a broad trough over eastern North America (Fig. 2). The trough axis is tilted from the northeast toward the southwest (positive tilt) so that its southern portion is located over northern Mexico. The strong north-south flow across the central portion of the country is responsible for the tendency toward dryness at all 3 locations (the percentage of days in the dry category ranging from 40 to $52 \%$ ). Circulation Type 2, the second most common type, also is a ridge-trough pattern, but the ridge is weaker and the trough line runs across the Great Lakes basin. It tends to be a wet type for Ohio and Georgia, located to the east of the trough line, but it is an indeterminate type for Lake Superior, for which dry, average, and wet days are almost equally likely. Circulation Type 3 is dominated by a deep upper-level vortex centered over eastern Canada, with the trough line located along the East Coast. It is an indeterminate type for Lake Superior and Ohio, but a dry type for Georgia. Circulation Type 4 features a trough over the central portion of the continent. The trough line displays a negative tilt in its northern segment and a positive tilt in the south. This type tends toward wetness at all 3 locations because all 3 are positioned east of the trough line. Circulation Type 5 is characterized by a West Coast trough and a weak ridge over the central portion of the continent that tends to promote dryness at all 3 locations.

It is tempting to compare these circulation types with some of the well-known teleconnection patterns (e.g. Wallace \& Gutzler 1981, Barnston \& Livezey 1987). Rohli et al. (1999), for example, developed a PC-based classification of $700 \mathrm{hPa}$ heights for a window similar to the one used here and correlated the PC scores with teleconnection indices. There are similarities between their map clusters and the circulation types in Fig. 3. For example, Circulation Types 1 and 3 and their cluster E are similar in that all three feature a deep trough over eastern North America. Rohli et al. (1999) found the occurrence of their cluster $\mathrm{E}$ to be related to the PNA index. However, only 2 of the 3 centers of action of the PNA pattern are located within or near the boundary of the map window used here; neither of the 2 centers of action of the North Atlantic Oscillation (NAO), a teleconnection pattern known to influence the climate of eastern North America, is located within that map window. In order to truly capture these teleconnection patterns, a very large window would be required. While it is desirable to use a window large enough to capture some of the larger-scale features of the general circulation, such as a trough or ridge, a large window would result in small-scale features being missed by the classification 

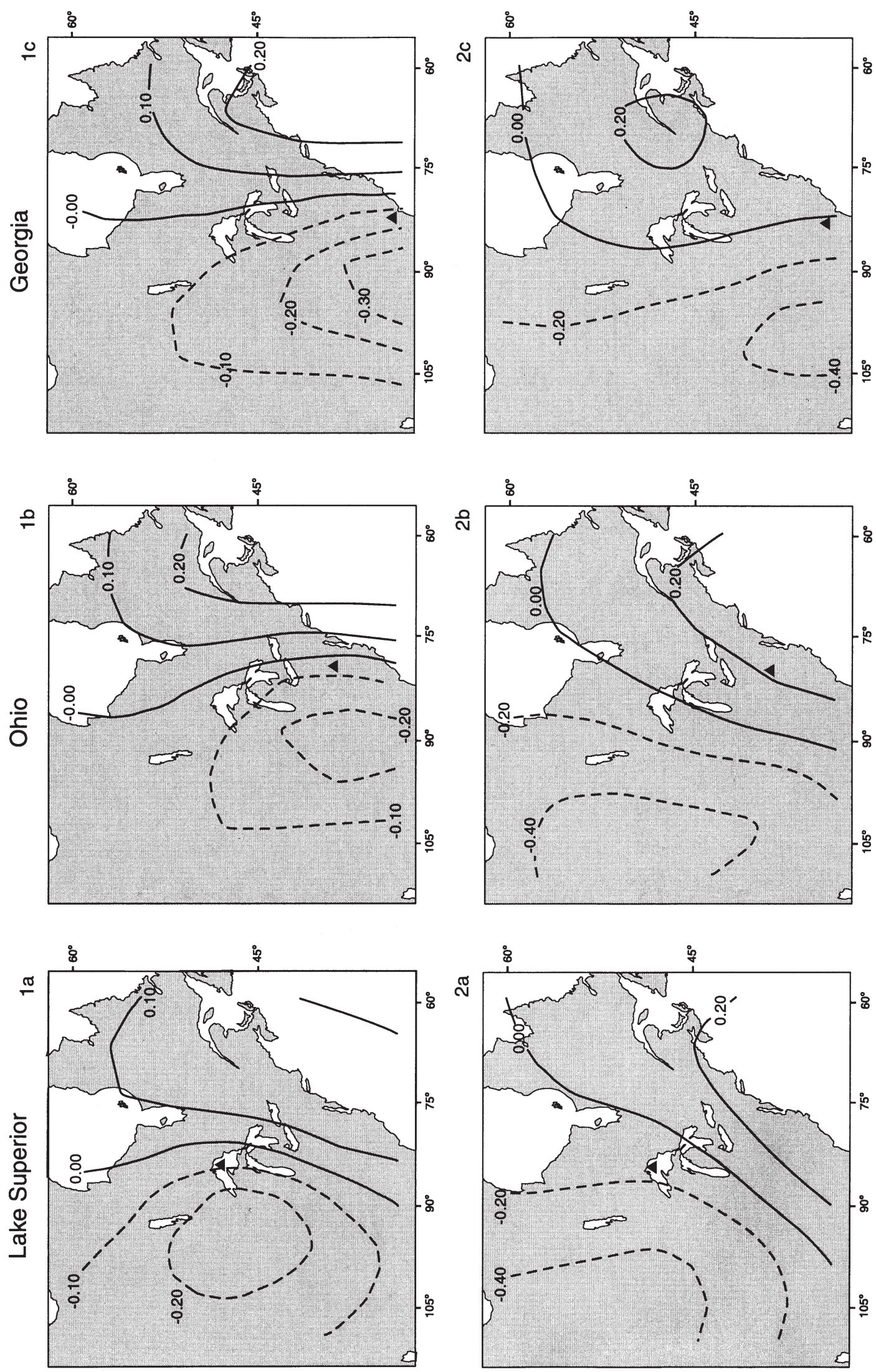

Daily

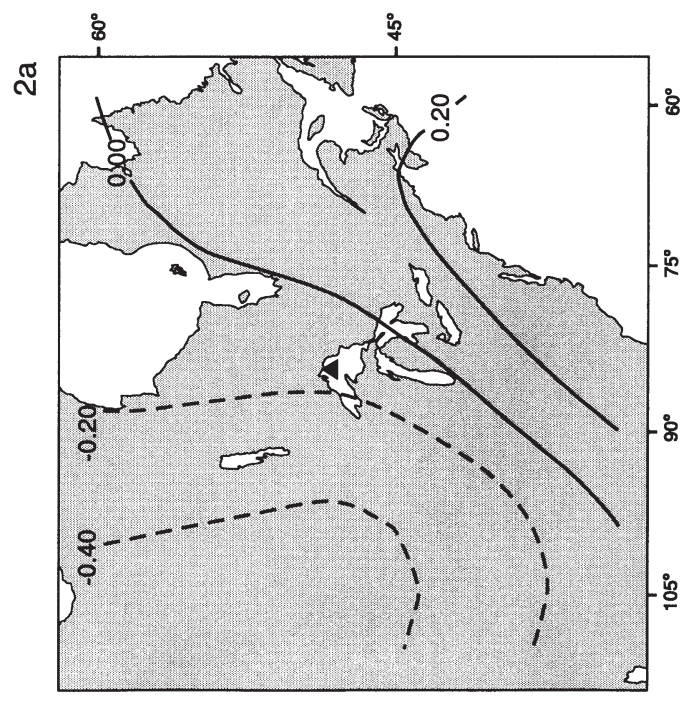

Monthly

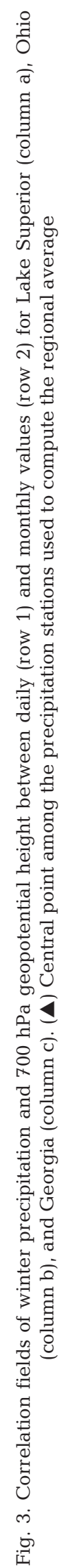



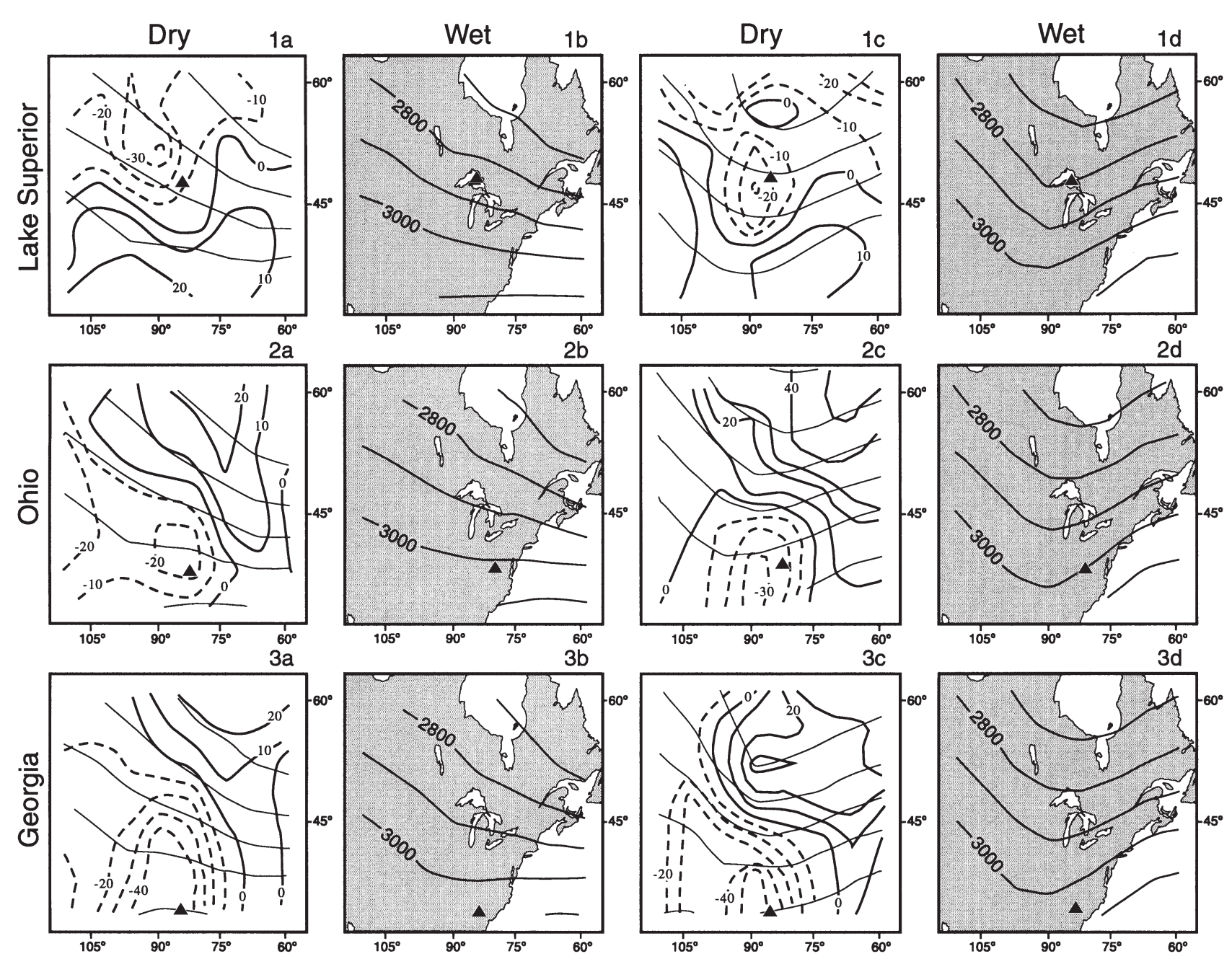

Fig. 4. $700 \mathrm{hPa}$ geopotential heights for the first 2 circulation types. For Circulation Type 1: dry composite (column a, thin lines), composite difference (column a, heavy lines), and wet composite (column b); for Circulation Type 2: dry composite (column c, thin lines), composite difference (column c, heavy lines), and wet composite (column d). Row 1 is for Lake Superior, row 2 for Ohio, and row 3 for Georgia (contour intervals are 10 dam for the composite maps and 1 dam for the composite difference maps).

(A) Central point among the precipitation stations used to compute the regional average

scheme. Small-scale circulation features can be very important in the generation of precipitation, as was shown in B00 for summer precipitation and will be documented here for winter precipitation. (It is worth noting, however, that the first 5 circulation types, comprising $50 \%$ of the days, all feature a ridge west of $100^{\circ} \mathrm{W}$, not a trough.)

Table 1 shows that none of the first 5 circulation types are perfectly wet types (i.e. $100 \%$ of the days belonging to that type are in the wet category) or perfectly dry types at any of the 3 locations. Even if one considers a type to be wet if at least $50 \%$ of the days are wet and a type to be dry if at least $50 \%$ of the days are dry (as was argued in B99a), only 1 or 2 map types per region can be identified as being either dry or wet. This problem is referred to as 'within-type' variability and is considered to be a very difficult but important challenge for synoptic climatology (Yarnal 1993). In B00, the cause of the large within-type variability of summer precipitation was investigated. It was found that the difference between wet and dry days of a circulation type is a negative height difference located to the west or northwest of Lake Superior. The fact that this was true for all circulation types led to the conclusion that the difference between wet and dry daysregardless of the circulation type-is a small-scale feature to the west of the lake, i.e. an approaching short-wave trough.

To determine whether this is also true for winter and for the other 2 precipitation regions, which would explain the local minima in the daily correlation fields, composite and composite difference maps were generated. Fig. 4 displays these maps for 2 different circulation types: a type featuring a strong northwesterly flow 
across eastern North America (Circulation Type 1), and a type featuring a trough over eastern North America (Circulation Type 2). The 3 rows of maps represent the results for the 3 precipitation regions. The location of the triangles represents the central point among the stations used for each region. The maps in column a are the dry composites (the average $700 \mathrm{hPa}$ height patterns for all dry days which are by definition among the driest one-third of the days of the entire record; see Section 2.1) for Circulation Type 1. The maps in col$\mathrm{umn} \mathrm{b}$ are the wet composites. Superimposed upon the dry composites are the contours of the composite differences $\left[Z_{\text {wet }}-Z_{\text {dry }}\right]$. The last 2 columns depict the dry (column c) and wet (column d) composites of Circulation Type 2. Superimposed upon the dry composites of Circulation Type 2 are the contours of the composite differences.

The difference between dry and wet days of a circulation type is in all cases an area of negative height anomalies centered to the west or northwest of the precipitation region, in the vicinity of the local minima (the central portion of the negative height differences are statistically significant at $\mathrm{p}<0.05$ ). In B00, such height anomalies for summer precipitation were viewed in terms of a small-scale circulation component that, when added to or subtracted from a circulation pattern, would modify that pattern in subtle but important ways that enhance the precipitation-generating characteristics of the circulation pattern. Fig. 4 shows that this is also true for winter and for all 3 precipitation regions. Circulation Type 1, for example, features a steep northwesterly flow immediately to the west and northwest of Lake Superior for dry days for that region (Fig. 4, column 1a). The lowered heights for wet days not only reduce the steepness of the flow but also appear to create a small trough (Fig. 4, column 1b). For Ohio and Georgia, Type 1 features a small trough within the northwesterly flow upstream of these regions for dry days; the lowered heights for wet days represent a move of these troughs eastward and closer to the precipitation regions. The trough line in Circulation Type 2-whose mean position is over the Great Lakes basin-is located east of Lake Superior for dry days and is shifted westward for wet days. For Ohio and Georgia, the shift of the trough for wet days is eastward and closer to the 2 precipitation regions.

The most obvious interpretation of these negative height differences is that they are a reflection of the presence of short-wave troughs. Traveling short waves play an important role in the generation of precipitation due to the large vorticity advection associated with them; upper-level troughs tend to be located to the west of surface lows because of the westward tilt of lows with altitude (e.g. Carlson 1991). Three approaches were used to test this notion. First, correla-

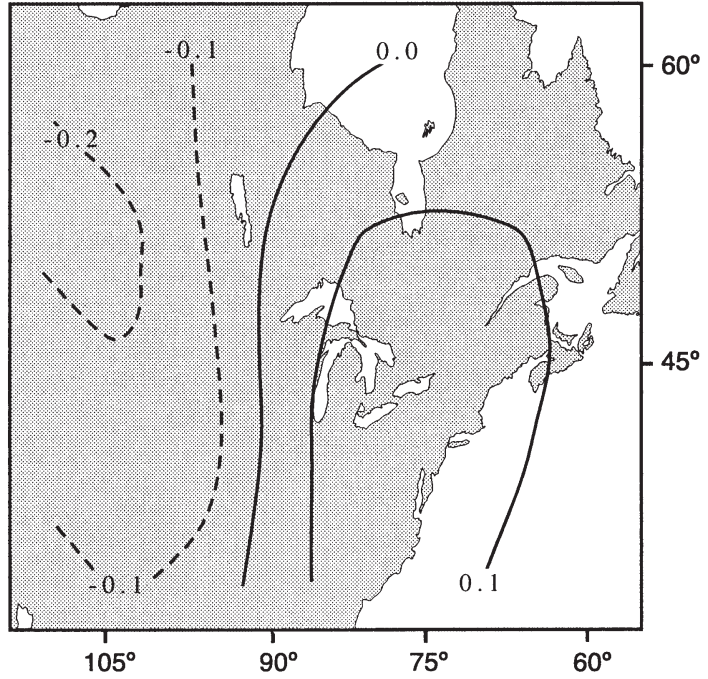

Fig. 5. Correlation field of daily precipitation for Lake Superior and $700 \mathrm{hPa}$ heights lagged by $1 \mathrm{~d}$

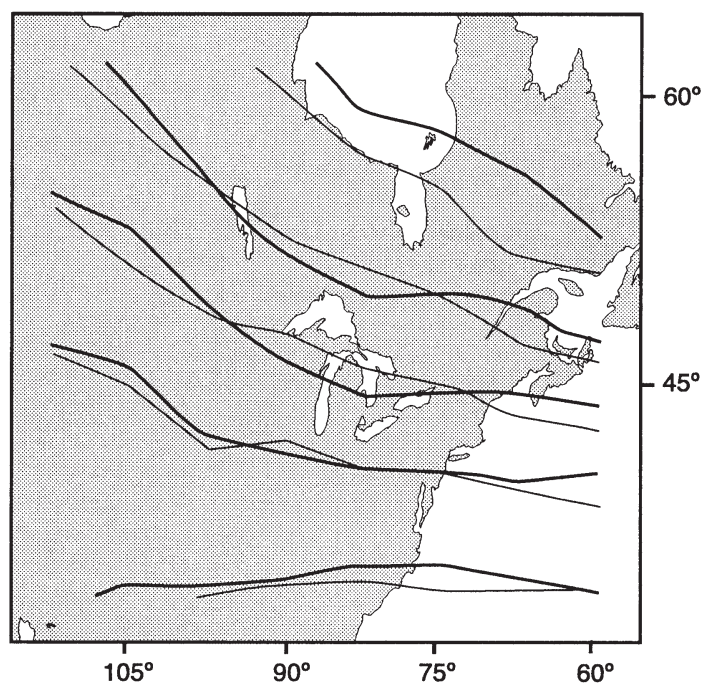

Fig. 6. Composite $700 \mathrm{hPa}$ heights for Circulation Type 1 for wet days over Lake Superior (heavy lines) and the preceding day if it was also a Type 1 (thin lines) (contour interval is 10 dam)

tion fields between daily precipitation and $700 \mathrm{hPa}$ heights lagged by $1 \mathrm{~d}$ showed a westward shift of the correlation minima (Fig. 5 shows the lagged correlation field for Lake Superior). Given the coarseness of the grid and the fact that the data are daily averages, the size of this westward shift is in agreement with Sanders (1988), who showed that short waves in this region travel at a rate of about $15^{\circ}$ of longitude per day. Second, the eastward progress of short-wave troughs on successive $700 \mathrm{hPa}$ maps was examined. Fig. 6 shows the results for Lake Superior for days with Cir- 
culation Type 1 if the day was wet and if the previous day was also a Circulation Type 1 day. A steepening of the heights to the west of the lake and a lowering in the vicinity of the lake during day 2 (the wet day) is evident. Third, a simple count of the number of days with positive vorticity (Eq. 1) at the local grid points showed that positive vorticity occurred on about two-thirds of the wet days, but on less than half that many of the dry days ( $p<0.05$, Mann-Whitney rank sum test). The somewhat imperfect match between positive vorticity and precipitation may be due to several factors including the coarse grid used here and the fact that Eq. (1) computes curvature vorticity, not shear vorticity or vorticity advection. Curvature vorticity is used here because the focus is on the minima in the $700 \mathrm{hPa}$ heights for wet days and wet months (i.e. the presence or absence of short waves) rather than on the precipitation mechanism, which is more directly linked to vorticity advection and vertical motion.

The conclusion to be drawn from these analyses is that the local minima in the daily correlation fields are due to negative height anomalies for wet days that, in turn, are a reflection of the presence of traveling short waves. These 'local' minima therefore have a physical meaning.

\subsection{Monthly time scale: remote minima}

The cause of the remote minima in the monthly correlation fields is explored using the 10 wettest and 10 driest months for each of the 3 precipitation regions. Their circulation type frequencies and precipitation characteristics, together with the mean height anomalies at the respective remote grid points, are displayed in Table 2 .

\subsubsection{Remote grid point height anomalies: wet versus dry months}

The mean height anomalies (differences from the long-term mean) at the remote grid points are in all cases positive for dry months and negative for wet months. To determine whether these anomalies are due to differences in the frequency of long-wave trough- or ridge-type circulation patterns, as suggested in K63, or due to smaller-scale variability such as short-wave troughs, the anomalies were decomposed into between-type and within-type components. For example, the occurrence of a circulation type featuring a ridge in the vicinity of the remote grid point will generate a positive height difference there, while a trough will generate a negative one, and changes in their frequencies generate between-type variability.
Table 2. Circulation type frequencies and precipitation characteristics as well as precipitation anomalies (fraction of the long-term mean) and mean height anomalies (m) for dry and wet months. $d=$ dry, $a=$ average, $w=$ wet

\begin{tabular}{|c|c|c|c|c|}
\hline \multirow[t]{2}{*}{ Circulation type } & \multicolumn{4}{|c|}{$\begin{array}{l}\text { Frequencies of circulation types and } \\
\text { precipitation categories }\end{array}$} \\
\hline & $\%$ & $\begin{array}{l}\text { Dry months } \\
(\mathrm{d} / \mathrm{a} / \mathrm{w})\end{array}$ & $\%$ & $\begin{array}{l}\text { Wet months } \\
(\mathrm{d} / \mathrm{a} / \mathrm{w})\end{array}$ \\
\hline \multicolumn{5}{|l|}{ Lake Superior } \\
\hline Type 1 & 17.1 & $(47 / 38 / 15)$ & 14.7 & $(40 / 34 / 26)$ \\
\hline Type 2 & 10.0 & $(59 / 16 / 25)$ & 13.2 & $(29 / 26 / 45)$ \\
\hline Type 3 & 9.3 & $(73 / 14 / 13)$ & 7.8 & $(24 / 24 / 52)$ \\
\hline Type 4 & 2.8 & $(67 / 0 / 33)$ & 11.0 & $(26 / 11 / 63)$ \\
\hline Type 5 & 10.3 & $(67 / 27 / 6)$ & 4.4 & $(50 / 0 / 50)$ \\
\hline All types & & $(55 / 25 / 20)$ & & $(29 / 21 / 50)$ \\
\hline Precipitation anor & maly & -0.535 & & 0.816 \\
\hline Mean height anor & maly & 17.3 & & -37.4 \\
\hline \multicolumn{5}{|l|}{ Ohio } \\
\hline Type 1 & 15.0 & $(67 / 23 / 10)$ & 16.4 & $(44 / 33 / 23)$ \\
\hline Type 2 & 7.1 & $(35 / 39 / 26)$ & 15.8 & $(8 / 28 / 64)$ \\
\hline Type 3 & 15.6 & $(37 / 49 / 14)$ & 5.0 & $(19 / 50 / 31)$ \\
\hline Type 4 & 3.1 & $(70 / 10 / 20)$ & 11.7 & $(14 / 24 / 62)$ \\
\hline Type 5 & 9.2 & $(50 / 47 / 3)$ & 4.7 & $(40 / 53 / 7)$ \\
\hline All types & & $(45 / 38 / 17)$ & & $(23 / 29 / 48)$ \\
\hline Precipitation anon & maly & -0.594 & & 0.654 \\
\hline Mean height anon & maly & 19.5 & & -21.5 \\
\hline \multicolumn{5}{|l|}{ Georgia } \\
\hline Type 1 & 19.1 & $(53 / 31 / 16)$ & 14.3 & $(45 / 25 / 30)$ \\
\hline Type 2 & 7.1 & $(35 / 52 / 13)$ & 13.7 & $(5 / 24 / 71)$ \\
\hline Type 3 & 15.4 & $(50 / 42 / 8)$ & 7.0 & $(39 / 35 / 26)$ \\
\hline Type 4 & 4.9 & $(38 / 31 / 31)$ & 9.4 & $(7 / 32 / 61)$ \\
\hline Type 5 & 9.6 & $(58 / 42 / 0)$ & 6.4 & $(57 / 38 / 5)$ \\
\hline All types & & $(45 / 39 / 16)$ & & $(26 / 32 / 42)$ \\
\hline Precipitation anon & maly & -0.597 & & 0.491 \\
\hline Mean height anon & maly & 19.0 & & -11.7 \\
\hline
\end{tabular}

The within-type variability is generated by deviations of the daily height above or below the mean for the circulation type to which the day belongs. The mean height anomaly at the remote grid point is thus the sum of the two, or

$$
\bar{P}_{\mathrm{w}}-\overline{\bar{P}}=\sum_{i=1}^{M}\left\{\Delta f\left(\bar{P}_{i}-\overline{\bar{P}}\right)+\left[\sum_{i=1}^{N}\left(P_{\mathrm{o}}-\bar{P}_{i}\right)\right] / N\right\}
$$

where $\overline{\bar{P}}$ is the long-term mean geopotential height at the remote grid point, $\bar{P}_{\mathrm{w}}$ is the mean height for the dry (wet) months, $\bar{P}_{i}$ is the mean for the $i$ th circulation type, $P_{\mathrm{o}}$ is the observed value, $M$ is the number of circulation types, $N$ is the number of days comprising the dry (wet) months, and $\Delta f$ is the difference in the relative frequency of occurrence of the $i$ th circulation type between the dry (wet) months and the entire data set.

The 2 components for each of the first 5 circulation types and 3 precipitation regions are presented in Table 3. The contribution to the mean height anomalies due to differences in frequency (the first term on 
the right-hand side of Eq. 3) is for almost all circulation types positive for dry months and negative for wet months. Circulation Type 2, for example, features a weaker than normal ridge to the west. This results in a $-36.4 \mathrm{~m}$ height difference between this map type and the long-term mean height at the remote grid point for Lake Superior. Circulation Type 2 occurs less frequently during dry months (compared to the long-term mean frequency) for Lake Superior $(\Delta f=-0.016$; see Tables $1 \& 2$ ). The product of the two is thus +0.58 . This type occurs more frequently during wet months for Lake Superior $(\Delta f=+0.016)$, and the product is -0.58 . For all 3 locations, the mean heights at the remote grid points for Circulation Types 2 and 4 are below the long-term mean and occur less frequently during dry months (Table 2), which results in a positive contribution to the mean height anomalies. They occur more frequently during wet months, and this generates a negative contribution. The opposite is true for Circulation Types 1, 3, and 5.

The second contribution to the mean height anomalies at the remote grid points, the variability about the

Table 3. The between-type and within-type contributions (m) to the mean height anomalies at the remote grid points for dry and wet months for the first 5 circulation types as well as the total and percent contribution from all types

\begin{tabular}{|c|c|c|c|c|}
\hline & \multicolumn{2}{|c|}{ Dry months } & \multicolumn{2}{|c|}{ Wet months } \\
\hline & Between & Within & Between & Within \\
\hline \multicolumn{5}{|c|}{ Lake Superior } \\
\hline Type 1 & 0.08 & 2.91 & -0.09 & -3.81 \\
\hline Type 2 & 0.58 & -0.97 & -0.58 & -2.98 \\
\hline Type 3 & 0.25 & 2.14 & -0.37 & -3.28 \\
\hline Type 4 & 1.43 & 0.06 & -1.50 & -0.80 \\
\hline Type 5 & 1.27 & 2.38 & -0.75 & -2.36 \\
\hline All types & 5.2 & 12.1 & -13.8 & -23.6 \\
\hline $\begin{array}{l}\% \text { of mean } \\
\text { anomaly }\end{array}$ & 30 & 70 & 37 & 63 \\
\hline \multicolumn{5}{|l|}{ Ohio } \\
\hline Type 1 & -0.09 & 1.49 & 0.04 & -4.48 \\
\hline Type 2 & 1.13 & 1.01 & -1.06 & -1.48 \\
\hline Type 3 & 2.87 & 0.80 & -1.54 & -0.26 \\
\hline Type 4 & 1.36 & 0.15 & -1.80 & -1.20 \\
\hline Type 5 & 0.72 & -0.10 & -0.53 & -0.14 \\
\hline All types & 13.6 & 5.9 & -7.9 & -13.6 \\
\hline $\begin{array}{c}\% \text { of mean } \\
\text { anomaly }\end{array}$ & 70 & 30 & 37 & 63 \\
\hline \multicolumn{5}{|l|}{ Georgia } \\
\hline Type1 & 0.57 & 2.06 & -0.28 & -3.00 \\
\hline Type2 & 0.57 & 2.92 & -0.26 & -1.47 \\
\hline Type 3 & 1.81 & -0.74 & -0.46 & -0.34 \\
\hline Type 4 & 0.55 & 0.84 & -0.75 & -1.13 \\
\hline Type 5 & 0.68 & 0.48 & -0.05 & -0.47 \\
\hline All types & 8.5 & 10.5 & -1.5 & -10.2 \\
\hline $\begin{array}{l}\% \text { of mean } \\
\text { anomaly }\end{array}$ & 45 & 55 & 13 & 87 \\
\hline
\end{tabular}

mean for the circulation type, is also for almost all circulation types positive for dry months and negative for wet months. This indicates that the daily $700 \mathrm{hPa}$ maps feature somewhat lower heights at the remote grid points (as compared to the average for the circulation type to which the map belongs) during wet months and higher heights during dry months. This within-type variability is the most important contributor to the negative mean height anomalies for wet months, ranging from 63 to $87 \%$. For dry months, the picture is not quite as clear; the contribution from within-type variability for those months ranges from 30 to $70 \%$. It must be noted, however, that the sum of the within-type variability for the entire data set is by definition equal to zero. Consequently, negative deviations for one subset require positive deviations for the other.

Three approaches were used to examine the nature of the negative within-type occurrences $(W-)$ at the remote grid points. First, $700 \mathrm{hPa}$ composite maps were generated for the dry and wet months for each of the 3 precipitation regions (not shown), their composite difference maps look very similar to the monthly correlation fields (Fig. 3). The relationship between geopotential heights and precipitation is, however, diluted in these monthly maps, because they filter out the synoptic variability (traveling short waves). This becomes clear when studying the weekly maps published in the Monthly Weather Review's 'Weather and Circulation' summaries. Wet months for the 3 precipitation regions are wet because of 1 or 2 wet weeks. A survey of daily upper-level maps for those weeks reveals that they are characterized by a series of short waves and an occasional long-wave trough tracking across the remote grid point. This is substantiated by several recent studies concerning upper-air cyclogenetic precursors that have documented the existence of short wave genesis regions in the lee of major mountain ranges, including the Rocky Mountains (Sanders 1988, Lefevre \& Nielsen-Gammon 1995, Dean \& Bosart 1996). Furthermore, that these are traveling waves is supported by the fact that the correlation between daily precipitation and $700 \mathrm{hPa}$ heights at the remote grid points is most negative at lag -1 for Lake Superior and lag -2 for Ohio and Georgia. It is, therefore, the frequent passage of troughs across the remote grid point rather than the presence of troughs at that grid point that is the link to wet conditions for the precipitation regions, which is a statistical rather than a dynamic link (i.e. it is due to dynamic tendencies).

Second, a simple count of the number of days with positive vorticity $(\mathrm{V}+)$ at the remote grid points showed that there is a significantly $(\mathrm{p}<0.05$, Mann-Whitney rank sum test) larger number of such days during wet months as compared to dry months for all 3 precipitation regions. 
The third approach evolved from the realization that, of the first 5 circulation types, the largest contributor to negative within-type variability during wet months was Type 1, which features an amplified ridge over the Rocky Mountains, not a long-wave trough (Table 3). This led to an investigation of the character of the circulation types most conducive to large contributions to the negative within-type variability (or $W-$ ) and what role vorticity is playing in these height depressions. This approach consisted of dividing all days with $W$ - into 4 circulation groups: (1) between-type variability is negative $(B-)$ and vorticity is positive $(V+)$; (2) between-type variability is negative ( $B-$ ) and vorticity is negative $(V-) ;(3)$ between-type variability is positive $(B+)$ and vorticity is positive $(V+)_{i}$ and (4) between-type variability is positive $(B+)$ and vorticity is negative $(V-)$.

$B+$ circulation patterns generally feature a strong western ridge (a positive height difference added to a long-term mean western ridge), while $B$ - circulation patterns feature a weak ridge, a westerly flow, or a western trough. The average within-type $(W)$ height deviations $\left(P_{\mathrm{o}}-P_{i}\right.$ in Eq. 3$)$ are shown in Table 4 for each of the 4 groups together with their relative frequencies $(f)$ and the product of the two, i.e. the withintype contribution from days with $W$ - to the mean height anomalies for dry and wet months.

The largest average height depressions below the type means, about 45 to $55 \mathrm{~m}$, are associated with the $B-V+$ and the $B+V+$ groups, while the average depressions for the 2 groups with negative vorticity are

Table 4. Within-type contribution to the mean height anomalies at the remote grid points for days with negative within-type $(W-)$ variability only, divided into 4 circulation groups according to the sign of the between-type variability $(B)$ and the sign of the vorticity $(V)$

\begin{tabular}{|lcccccc|}
\hline & \multicolumn{3}{c}{ Dry months } & \multicolumn{3}{c|}{ Wet months } \\
& $P_{\mathrm{o}}-P_{i}$ & $f$ & $f\left(P_{\mathrm{o}}-P_{i}\right)$ & $P_{\mathrm{o}}-P_{i}$ & $f$ & $f\left(P_{\mathrm{o}}-P_{i}\right)$ \\
\hline $\boldsymbol{B}$ - and $\boldsymbol{V +}$ & & & & & & \\
Lake Superior & -54.9 & 0.12 & -6.5 & -58.8 & 0.26 & -15.5 \\
Ohio & -44.2 & 0.10 & -4.4 & -44.1 & 0.18 & -8.1 \\
Georgia & -38.9 & 0.09 & -3.5 & -51.9 & 0.21 & -10.7 \\
$\boldsymbol{B}$ - and $\boldsymbol{V}$ - & & & & & & \\
Lake Superior & -34.4 & 0.03 & -1.2 & -40.4 & 0.08 & -3.2 \\
Ohio & -19.2 & 0.06 & -1.2 & -35.3 & 0.17 & -4.9 \\
Georgia & -20.1 & 0.03 & -0.6 & -32.7 & 0.06 & -2.1 \\
$\boldsymbol{B}+$ and $\boldsymbol{V +}$ & & & & & & \\
Lake Superior & -56.2 & 0.12 & -6.7 & -74.1 & 0.17 & -12.3 \\
Ohio & -45.2 & 0.08 & -5.2 & -68.5 & 0.11 & -7.5 \\
Georgia & -57.3 & 0.08 & -4.6 & -56.3 & 0.15 & -8.2 \\
B+ and $\boldsymbol{V}$ - & & & & & & \\
Lake Superior & -40.6 & 0.07 & -2.7 & -40.5 & 0.11 & -4.3 \\
Ohio & -36.4 & 0.03 & -4.9 & -15.0 & 0.09 & -1.3 \\
Georgia & -25.4 & 0.07 & -4.4 & -32.2 & 0.11 & -3.5 \\
\hline
\end{tabular}

about $20 \mathrm{~m}$ less. Since the members of these 4 groups had to be associated with $W$ - and such members or days are more frequent during wet months, all 4 groups are about twice as frequent during wet months. However, because of the larger average height depressions for the groups with positive vorticity, these 2 groups are the major contributors for wet months. The contribution from a simple lowering of the heights without the generation of positive curvature vorticity ( $W$-days with $V-$ ) from the $B+$ and $B$-types combined barely approaches the magnitude of the contribution from either $B-V+$ or $B+V+$. Height depressions associated with positive vorticity, regardless of the circulation type, are therefore key for wet months.

The overall conclusion to be drawn from these analyses is that the correlation minima at the remote grid points in the monthly fields are mainly due to the tendency for short waves to travel across the remote grid points during wet months. This conclusion is supported by the fact that the location of these 3 grid points, and in fact the location of many of the minima in the $700 \mathrm{hPa}$ heights shown in Fig. 1, coincides with the well-known North American cyclogenetic region in the lee of the Rocky Mountains and the western edge of the region of frequent surface cyclones (Zishka \& Smith 1980, Diaz \& Fulbright 1981, Whittaker \& Horn 1984, Changnon et al. 1995). The location of the remote grid point for Lake Superior, over southern Alberta and Saskatchewan, coincides with the beginning of the Alberta Clipper storm track. The location of the remote grid point for Ohio, over Montana, could be a reflection of the combined influence of the Alberta and Colorado tracks. The location of the remote grid point for Georgia, over central Texas, coincides with the beginning of the Gulf Coast storm track.

It is interesting to note that cyclogenesis to the east of the Rocky Mountains does not appear to be spatially uniform and/or there are shifts in the upper-level steering current (which frequently splits into a northern and a southern component in winter) because the 3 precipitation regions do not share many of their wet months. Only 2 of the 10 wettest months for Lake Superior are also among the 10 wettest for Ohio; only 2 of the 10 wettest months for Ohio are also among the 10 wettest for Georgia; and Lake Superior and Georgia share only 2 wet months and these are not shared with Ohio. 


\subsubsection{Precipitation characteristics: wet versus dry months}

Comparison of Tables $1 \& 2$ shows that, as expected, wet circulation types are more frequent during wet months and dry types are more frequent during dry months. It is, however, surprising to find that all circulation types are drier during dry months (i.e. they contain more dry days) and are wetter during wet months. Furthermore, this change in precipitation characteristics is for 4 cases so large that their characteristics flip between wet and dry months. For example, for Lake Superior and Circulation Type 4, 67\% of the days of that type are dry and $33 \%$ are wet during dry months, but during wet months $26 \%$ of the days are dry and $63 \%$ are wet (Table 2). For Lake Superior, such a flip occurs in Circulation Types 2, 3 and 4. The same flip occurs with Circulation Type 4 for Ohio. Thus, changes in the frequency of occurrence of dry and wet circulation types as well as changes in their precipitation characteristics lead to dry and wet months. To determine which is more important, the between-type and within-type contributions to the mean precipitation anomalies were computed using Eq. (3), and the results are displayed in Table 5 .

The contribution to the mean precipitation anomalies due to differences in frequency is for all circulation types positive for wet months and negative for dry months. Circulation Types 2 and 4, for example, occur more frequently during wet months (Table 2), and their long-term mean precipitation anomalies are positive, i.e. days belonging to these types are most frequently wet (Table 1). The product of the two-the betweentype variability - is therefore positive for all 3 precipitation regions. Conversely, Circulation Types 1, 3 and 5 , are dry types, and they occur less frequently during wet months; their contribution is therefore also positive during wet months. However, between-type variability is, for both wet and dry months, considerably smaller than within-type variability - the tendency for all types to be wetter during wet months and drier during dry months. This is particularly true for wet months, for which within-type variability contributes 85 to $93 \%$ toward the mean precipitation anomalies. Within-type variability contributes only 56 to $67 \%$ toward the mean anomalies for dry months.

The conclusion to be drawn from this is that the difference between wet and dry months is not so much a difference in the frequency of occurrence of wet and dry circulation types as it is a change in their precipitation-generating characteristics. This is, of course, only an apparent change, since it is easily explained in terms of short-wave troughs immediately to the west of the precipitation regions during wet days.
Table 5. Between-type and within-type contributions to the mean precipitation anomalies for dry and wet months for the first 5 circulation types as well as the total and percent contribution from all types

\begin{tabular}{|c|c|c|c|c|}
\hline & \multicolumn{2}{|c|}{ Dry months } & \multicolumn{2}{|c|}{ Wet months } \\
\hline & Between & Within & Between & Within \\
\hline \multicolumn{5}{|c|}{ Lake Superior } \\
\hline Type 1 & -0.0041 & -0.0377 & 0.0048 & 0.0230 \\
\hline Type 2 & -0.0000 & -0.0601 & 0.0000 & 0.0682 \\
\hline Type 3 & -0.0011 & -0.0432 & 0.0016 & 0.0294 \\
\hline Type 4 & -0.0196 & -0.0195 & 0.0205 & 0.0721 \\
\hline Type 5 & -0.0164 & -0.0367 & 0.0098 & 0.0662 \\
\hline All types & -0.2338 & -0.3008 & 0.1233 & 0.6931 \\
\hline $\begin{array}{c}\% \text { of mean } \\
\text { anomaly }\end{array}$ & 44 & 56 & 15 & 85 \\
\hline \multicolumn{5}{|l|}{ Ohio } \\
\hline Type 1 & 0.0049 & -0.0432 & -0.0019 & 0.0217 \\
\hline Type 2 & -0.0304 & -0.0544 & 0.0284 & 0.1616 \\
\hline Type 3 & -0.0354 & -0.0272 & 0.0190 & 0.0106 \\
\hline Type 4 & -0.0222 & -0.0420 & 0.0295 & 0.0840 \\
\hline Type 5 & -0.0194 & -0.0096 & 0.0142 & 0.0017 \\
\hline All types & -0.2005 & -0.3939 & 0.0728 & 0.5810 \\
\hline $\begin{array}{c}\% \text { of mean } \\
\text { anomaly }\end{array}$ & 34 & 66 & 11 & 89 \\
\hline \multicolumn{5}{|l|}{ Georgia } \\
\hline Type 1 & -0.0141 & -0.0461 & 0.0070 & 0.0764 \\
\hline Type 2 & -0.0436 & -0.1029 & 0.0203 & 0.1722 \\
\hline Type 3 & -0.0340 & -0.0372 & 0.0086 & 0.0059 \\
\hline Type 4 & -0.0063 & -0.0181 & 0.0085 & 0.0715 \\
\hline Type 5 & -0.0224 & -0.0180 & 0.0015 & 0.0083 \\
\hline All types & -0.1969 & -0.4006 & 0.0335 & 0.4575 \\
\hline $\begin{array}{c}\% \text { of mean } \\
\text { anomaly }\end{array}$ & 33 & 67 & 7 & 93 \\
\hline
\end{tabular}

\section{SUMMARY AND DISCUSSION}

This study sought to examine the nature of the negative height differences between dry and wet days and between dry and wet months.

Analysis of the association between precipitation and $700 \mathrm{hPa}$ heights at the daily time scale, using correlation fields and composite maps, showed that wet days tend to be associated with height depressions immediately to the west or northwest of the precipitation region. This is true for all 3 regions and regardless of whether the circulation is a long-wave trough- or ridge-type pattern; in addition, it confirms the results of B00 for summer precipitation over Lake Superior. These height depressions for wet days were in most cases found to be associated with positive curvature vorticity and to represent traveling short-wave troughs. The minima in the $700 \mathrm{hPa}$ heights at a grid point immediately to the west or northwest of the precipitation region for wet days therefore have a physical or dynamic cause; and this should remain unchanged in a changed climate. 
The nature of the remote minima at the monthly time scale was examined using the 10 wettest and 10 driest months for each of the 3 precipitation regions. The height differences at their respective western or remote grid points were decomposed into betweentype and within-type contributions. The results show that, while some of the height depressions during wet months are due to an increased frequency of circulation patterns with below-normal heights at the remote grid points, such as weak ridges or troughs, more than two-thirds of the contribution comes from height depressions superimposed upon the larger-scale circulation patterns. These height depressions were in most cases found to be associated with positive curvature vorticity. The fact that the locations of the remote grid points (and most of the correlation minima in Fig. 1) coincide with a well-known region of frequent upperlevel cyclogenetic precursors and surface cyclogenesis supports the conclusion that the negative correlation between monthly precipitation totals and $700 \mathrm{hPa}$ heights at the remote grid points are due to a high frequency of traveling short-wave troughs during wet months.

These results have several implications with respect to the growing work on downscaling. First, they indicate that the optimum grid point location is a function of the time scale. At the daily time scale, the best grid point is not the one located within the region for which the precipitation is predicted but a point somewhat to the west or northwest of it. On a longer time scale, the optimum - at least for North American precipitationis a remote grid point. It is noteworthy that the significance of the remote North American grid points has a statistical rather than dynamic basis; and this might be one example of an association that may not hold in a changed climate if the prevailing upper-level flow is changed. It should also be noted that the optimum grid point location is a function of the parameter of interest. As shown in B99a and B00, the optimum location for daily temperature-at least for the Lake Superior basin-is to the east and southeast, reflecting the advection of warm air.

Second, a growing body of the downscaling work is focused not on a single grid point but on large-scale circulation patterns, since the skill of general circulation models is believed to be higher at the multiple rather than the single grid point level. Thus daily maps are frequently used, which requires some data reduction, such as grouping them into types or decomposing them into components. While it might be expected that similar circulation types or similar combinations of components generate similar surface weather conditions, this has often not been found to be true. Yarnal (1993) discussed a number of potential causes of the problem, such as grid point density, the size of the map window, the minimum number of members needed to define a type, and the need to assign discrete intervals to continuous data. The present work (as well as the work presented in B99a, B00, Brinkmann 1999b) highlights another cause, i.e. the fact that circulation pattern data reduction must by definition focus on the large-scale features and must ignore small-scale differences. Small-scale features can, however, be extremely important. In B99a and B00, for example, it was shown that a $700 \mathrm{hPa}$ height anomaly to the east of Lake Superior differentiates between cold and warm days of all circulation types for both winter and summer. In B00 it was shown that a height anomaly to the west of Lake Superior differentiates between dry and wet days of all summer circulation types. The present work showed that the latter is also true for winter and that, furthermore, it is also true for at least 2 other North American precipitation regimes. An attempt to capture the small-scale features by decomposing the $700 \mathrm{hPa}$ heights into principal components showed that they tend to appear in the less significant higherorder components and are therefore lost (Brinkmann 1999b). An attempt to include them in a modified classification by increasing the correlation threshold for those critical grid points in a correlation-based typing approach resulted in a very large number of unclassified days (B00).

It is not surprising, therefore, to find that what differentiates wet from dry months for all 3 North American precipitation regimes is not a difference in the frequency of circulation types, which are not able to capture the important small-scale features, but an apparent change in the their precipitation characteristics. Changes in characteristics rather than in frequencies of map types have also been identified for surface temperature associated with $500 \mathrm{hPa}$ patterns over the Pacific Northwest (Yarnal 1985) and with sea level pressure patterns over England (Sowden \& Parker 1981), as well as for precipitation associated with sealevel-pressure patterns over Switzerland (Widmann \& Schar 1997). The fact that a number of studies have found very small changes in circulation type frequencies between control and perturbed $\left(2 \times \mathrm{CO}_{2}\right)$ model runs further highlights the seriousness of the problem (Hay et al. 1992, Matyasovszky et al. 1993, Goodess \& Palutikof 1998).

Acknowledgements. The author thanks 3 reviewers whose comments greatly improved the final manuscript.

\section{LITERATURE CITED}

Bardossy A, Plate EJ (1992) Space-time model for daily rainfall using atmospheric circulation patterns. Water Resour Res 28:1247-1259 
Barnston AG, Livezey RE (1987) Classification, seasonality and persistence of low-frequency atmospheric circulation patterns. Mon Weather Rev 115:1083-1126

Bonsal BR, Zhang X, Hogg WD (1999) Canadian Prairie growing season precipitation variability and associated atmospheric circulation. Clim Res 11:191-208

Brinkmann WAR (1999a) Within-type variability of $700 \mathrm{hPa}$ winter circulation patterns over the Lake Superior Basin. Int J Climatol 19:41-58

Brinkmann WAR (1999b) Application of non-hierarchically clustered circulation components to surface weather conditions: Lake Superior basin winter temperatures. Theor Appl Climatol 63:41-56

Brinkmann WAR (2000) Modification of a correlation-based circulation pattern classification to reduce within-type variability of temperature and precipitation. Int J Climatol 20:839-852

Burnett AW (1994) Regional-scale troughing over the southwestern United States: temporal climatology, teleconnections, and climatic impact. Phys Geogr 15:80-98

Carlson TN (1991) Mid-latitude weather systems. Harper Collins Academic, London

Cavazos T (1999) Large-scale circulation anomalies conducive to extreme precipitation events and derivation of daily rainfall in northeastern Mexico and southeastern Texas. J Clim 12:1506-1523

Cayan DR, Roads JO (1984) Local relationships between United States west coast precipitation and monthly mean circulation parameters. Mon Weather Rev 112:1276-1282

Changnon D, Noel JJ, Maze LH (1995) Determining cyclone frequencies using equal-area circles. Mon Weather Rev 123:2285-2294

Crane RG, Hewitson BC (1998) Doubled $\mathrm{CO}_{2}$ precipitation changes for the Susquehanna Basin: down-scaling from the genesis general circulation model. Int J Climatol 18: 65-76

Dean BD, Bosart LF (1996) Northern Hemisphere 500-hPa trough merger and fracture: a climatology and case study. Mon Weather Rev 124:2644-2670

Diaz HF, Fulbright DC (1981) Eigenvector analysis of the seasonal temperature, precipitation and synoptic-scale system frequency over the contiguous United States. Part I: Winter. Mon Weather Rev 109:1267-1284

Easterling DR (1999) Development of regional climate scenarios using a downscaling approach. Clim Change 41: 615-634.

Giorgi F, Mearns LO (1991) Approaches to the simulation of regional climate change: a review. Rev Geophys 29: 191-216

Goodess CM, Palutikof JP (1998) Development of daily rainfall scenarios for southeast Spain using a circulation-type approach to downscaling. Int J Climatol 18:1051-1083

Harnack RP, Lanzante JR (1985) Specification of United States seasonal precipitation. Mon Weather Rev 113: 319-325

Hay LE, McCabe GJ Jr, Wolock DM, Ayers MA (1992) Use of weather types to disagregate general circulation model predictions. J Geophys Res (D3) 97:2781-2790

Hewitson BC, Crane RG (1996) Climate downscaling: techniques and applications. Clim Res 7:85-95

IPCC (Intergovernmental Panel on Climate Change) (1996) Climate Change 1995: the science of climate change. Cambridge University Press, Cambridge

Karl TR, Wang WC, Schlesinger ME, Knight RW, Portman D (1990) A method of relating general circulation model simulated climate to the observed local climate. Part I: Seasonal statistics. J Clim 3:1053-1079
Klein WH (1963) Specification of precipitation from the 700millibar circulation. Mon Weather Rev 91:527-536

Klein WH, Bloom HJ (1987) Specification of monthly precipitation over the United States from the surrounding $700 \mathrm{mb}$ height field. Mon Weather Rev 115:2118-2132

Klein WH, Bloom HJ (1989) An operational system for specifying monthly precipitation amounts over the United States from the field of concurrent mean 700 -mb heights. Weather Forecast 4:51-60

Leathers DJ, Yarnal B, Palecki MA (1991) The Pacific/North American teleconnection pattern and Unite States climate: Part I: Regional temperature and precipitation associations. J Clim 4:517-528

Lefevre RJ, Nielsen-Gammon JW (1995) A objective climatology of mobile troughs in the Northern Hemisphere. Tellus 47A:638-655

Lund IA (1963) Map-pattern classification by statistical methods. J Appl Meteorol 2:56-65

Matyasovszky I, Bogardi I (1994) Comparison of 2 general circulation models to downscaling temperature and precipitation under climate change. Water Resour Res 30: $3437-3448$

Matyasovszky I, Bogardi I, Bardossy A, Duckstein L (1993) Estimation of local precipitation statistics reflecting climate change. Water Resour Res 29:3955-3968

Palutikof JP, Winkler JA, Goodess CM, Andresen JA (1997) The simulation of daily temperature series from GCM output. Part I: Comparison of model data with observations. J Clim 10:2497-2513

Portman DA, Wang WC, Karl TR (1992) Comparison of general circulation model and observed regional climates: daily and seasonal variability. J Clim 5:343-353

Redmond KT, Koch RW (1991) Surface climate and streamflow variability in the western United States and their relationship to large-scale circulation indices. Water Resour Res 27:2381-2399

Robertson AW, Ghil M (1999) Large-scale weather regimes and local climate over the western United States. J Clim 12:1796-1813

Rohli RV, Vega AJ, Binkley MR, Britton SD, Heckman HE, Jenkins JM, Ono Y, Sheeler DE (1999) Surface and 700 $\mathrm{hPa}$ atmospheric circulation patterns for the Great Lakes basin and eastern North America and relationships to atmospheric teleconnections. J Great Lakes Res 25:45-60

Sailor DJ, Li X (1999) A semiempirical downscaling approach for predicting temperature impacts associated with climatic change. J Clim 12:103-114

Sanders F (1988) Life history of mobile troughs in the upper westerlies. Mon Weather Rev 116:2629-2648

Sowden IP, Parker DE (1981) A study of climate variability of daily central England temperatures in relation to the Lamb synoptic types. J Climatol 1:3-10

Stidd CK (1954) The use of correlation fields in relating precipitation to circulation. J Meteorol 11:202-213

Trewartha GT (1981) The earth's problem climates. The University of Wisconsin Press, Madison, WI

Wallace JM, Gutzler DS (1981) Teleconnections in the geopotential height field during the Northern Hemisphere winter. Mon Weather Rev 109:784-812

Walsh JE, Richman MB, Allen DW (1982) Spatial coherence of monthly precipitation in the United States. Mon Weather Rev 110:272-286

Whittaker LM, Horn LH (1984) Northern Hemisphere extratropical cyclone activity for 4 mid-season months. J Climatol 4:297-310

Widmann M, Schar C (1997) A principal component and longterm trend analysis of daily precipitation in Switzerland. 
Int J Climatol 17:1333-1356

Wigley TML, Jones PD, Briffa KR, Smith G (1990) Obtaining sub-grid-scale information from coarse-resolution general circulation model output. J Geophys Res 95(D2): 1943-1953

Wilby RL, Wigley TML (1997) Downscaling general circulation model output: a review of methods and limitations. Prog Phys Geogr 21:530-548

Yarnal B (1984) The effect of weather map scale on the results of a synoptic climatology. J Clim 4:481-493

Yarnal B (1985) A 500mb synoptic climatology of Pacific north-west coast winters in relation to climatic variability, 1948-1949 to 1977-1978. J Climatol 5:237-252

Editorial responsibility: Brent Yarnal, University Park, Pennsylvania, USA
Yarnal B (1993) Synoptic climatology in environmental analysis. Belhaven Press, London

Yarnal B, Leathers DJ (1988) Relationships between interdecadal and interannual climatic variations and their effect on Pennsylvanian climate. Ann Assoc Am Geogr 78: 624-641

Zishka KM, Smith PJ (1980) The climatology of cyclones and anticyclones over North America and surrounding ocean environs for January and July, 1950-77. Mon Weather Rev 108:387-401

Zorita E, von Storch H (1999) The analog method as a simple statistical downscaling technique: comparison with more complicated methods. J Clim 12:2474-2489

Submitted: July 31, 2000; Accepted: September 3, 2001

Proofs received from author(s): March 12, 2002 